writers who did not take this method we may be allowed to read between the lines. A leading ornithologist (Alfred Newton, if I am not mistaken), suggests that in the case of Linnæus we be allowed to ask the author what type he would have chosen if the modern problem were to be presented to him. As to this we should not be often left in doubt. If we are in doubt however, there is a very simple rule followed widely by naturalists, notably by Bleeker, the most voluminous writer on fishes. This is the selection, as type, of the first species named under the genus by its author, when other indications fail. This rule gives fixity, the sole essential thing. It gives justice. It saves a profitless overhauling of bibliography, and it is a clear way out of confusion. It is the only possible clear way.

I suggest for consideration the following provisional rules for the application of this method :

1. The type of a genus is the species designated as such by its author.

2. If no type is designated by the author, either explicitly or by clear implication, then the first species referred to the genus or the species standing first on the page, shall be considered as its type. A generic name should have no standing, if resting on definition alone, nor until associated with some definite species.

3. To this rule the following provisional exceptions may be made. The type of each genus of Linnæus as stated by him is 'the best known European or officinal species' it contains. In case of doubt in the application of this rule, the species standing first may have the benefit of the doubt. Unlike most subsequent authors, Linnæus usually placed his type species near the middle in the list of species. Cuvier made it his 'chef de file.'

4. In case of genera based on old specific names (Belone, Achirus, Trachurus) the species thus furnishing the name, if actu- ally mentioned by the author of the genus, may be regarded as its type.

5. Possibly, to avoid confusion, it may be well to retain old generic names, restricted by common consent to a species not the first mentioned by the author, provided that such restriction antedates any modern names for the same genus. Thus it may be well to retain Centropomus for Oxylabrax, instead of Lucioperca, Cheilodipterus for Paramia, instead of Pomatomus, Pomacanthus, for Pomacanthodes, instead of Zanclus. But I doubt the wisdom of this exception, and I shall not be surprised to see future writers following Bleeker in the use of Oxylabrax and Paramia, leaving the generic names of Lacépède and of all writers since Linnæus, to the first species named by their author. David Starr Jordan.

\section{NOTE ON THE NUMBER OF PARTICLES IN THE SATURATED PHOSPHORUS EMANATION.*}

In a series of experiments made by passing air ionized to saturation by phosphorus through a slender tubular condenser (60 $\mathrm{cm}$. long, radii of air space, $.30 \mathrm{~cm}$. and .16 cm.), I showed that the electrical current radially through the condenser for a given potential difference, and the volume per minute of the ionized air sent longitudinally through it, were rigorously proportional quantities. At the same time the color of the steam tube observed on passing the air from the condenser into it, was invariable no matter whether the condenser was charged or not, coet. par. Hence only an insignificant part of the particles producing condensation takes part in the electric current even with radial fields of 2,100 volts per cm., the highest safely admissible. I have estimated that less than 5 per cent. of

* Preceding experiments in Science, Feb. 9, 1900, the above note being a sequel. I there gave relative values for the absorption velocities, absolute values being given in the Am. Journ. of Science, March, 1900. 
the ions could have been destroyed by the electric transfer; otherwise the steam tube would have shown perceptible variation of color.

In connection with this result I have questioned whether the importance of the mutual destruction or decay of the ions has not been overestimated; whether the phe. nomenon of leakage in a plate condenser may not be very fully explained $*$ by taking account of the ions which wander laterally out of the field of force. . Let $A$ be the area of the condenser of air space $x$, and let $a x$ be the circumferential area terminating in the edges of the condenser (mantel of the cylinder of air). If one of the plates is a phosphorus grid (thin pellets of phosphorus secured between appressed discs of wire gauze), let $n$ be the number of particles per cubic centimeter at a normal distance $x$ from the grid. Let $k$ be the (absorption) velocity of the ions in the absence of an electrical field when passing from a saturated region either into free air or normally to an absorbing surface, and $k^{\prime} n^{2}$ the number decaying per cubic centimeter per second.

Remembering that in such a condenser there is lateral loss of ions escaping from between the plates, as well as the loss upon the plates whether the (phosphorus) condenser be charged electrically or not, the differential equation meeting the case is $-d n / d x=n\left(a / A+n k^{\prime} / k\right)$. This is integrable in finite form, and if $n_{0}$ be the number of ions per cubic centimeter at the phosphorus plate (saturation), the equation becomes $n / n_{0}=(a / A) /\left(\left(a / A+n_{0} k^{\prime} / k\right) \varepsilon^{(a / A) x}-\right.$ $\left.n_{0} k^{\prime} / k\right)$. If $k^{\prime}=0$, decay within the ionized space is ignored and $n=n_{0} / \varepsilon^{a x / A}$. Thus $n$ is independent of the absorption velocity $k$, depending for a given initial saturation $n_{0}$ only upon the mantel $(a x)$ and the base $(A)$ areas of the condenser air space.

Now let the condenser be charged, re-

* See my paper in the Physical Review, X., p. 257, 1900 , whence the data of this paper are taken. membering that the additional loss from this cause alone is insignificant. Let $V$ be the potential difference at the time $t, C$ the effective capacity, $U$ the relative or mutual velocity of the ions, $e$ the charge of each. Then $-d V / d t=A U V n e / C x$, or from the value of $n,-d V / d t=\left(A U V n_{0} e / C\right) / x \varepsilon^{a x / A}$.

In my data given in the Physical Review (1. c., Table III.) I put, as usual for leakages, $V=V_{0} 10^{-c t}$, whence $c$ was computed. Substituting this in the preceding equation, it reduces to $c=\left(A U n_{0} e / C \ln 10\right)\left(1 / x \varepsilon^{\alpha x / 4}\right)$.

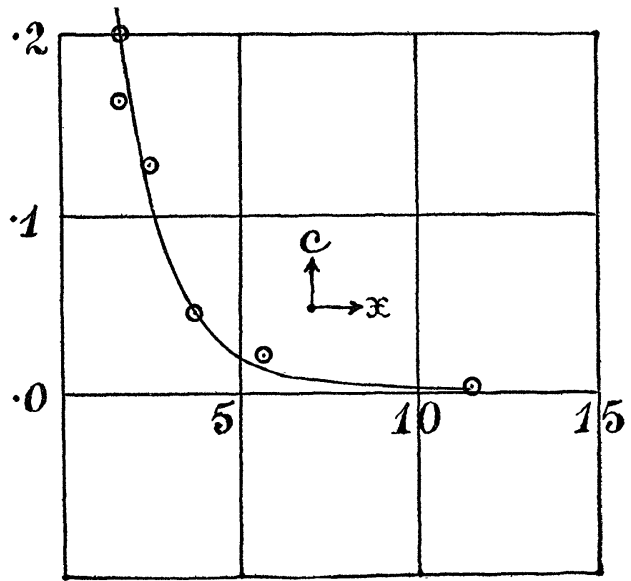

In the annexed diagram I have drawn this curve and distributed the observations with reference to it by so determining the constant $A U n_{0} e / C l n 10$, that the first observations coincide $(c=.200, x=1.7)$. The agreement of the theoretical curve and the observations is so striking as to give great probability to the hypothesis that decay $*$ is here relatively insignificant.

It is even possible to make an approach toward computing the constant, which since $c$ in my observations is taken rela-

* How much importance is to be attached to this decay $\left(k^{\prime}\right)$ I shall show in experiments with spherical condensers in which the ions can not escape. These results, while giving no evidence of decay, show that dilution (since saturation must fall off at increasing distances from a central phosphorus emanator) is accompanied by additional ionization; $i$. $e$, there is relatively too much current, cæt. par., when the spherical condenser is larger. 
tive to minutes instead of seconds, now becomes $K=26 A U n_{0} e / C$. For if the velocity of the ions produced by phosphorus is like that of other gaseous ions, $U$ is of the order (say) of $1 \mathrm{~cm} . / \mathrm{sec}$ (Rutherford, Townsend, Chattock) and $e$ of the order of $7 \times 10^{-10}$ electrostatic units or $2.4 \times 10^{-19}$ coulombs. The ratio of areas in my condenser was .35 , the area $A=132 \mathrm{~cm}^{2}$.; the capacity $C$ about $90 \mathrm{~cm}$. or $10^{-10}$ farads. Finally the observed value of $K$ as used in computing the above curve was $K=.634$. Thus the initial saturation $n_{0}=.634 \times 10^{-10} / 26 \times$ $132 \times 1 \times 2.4 \times 10^{-19}=8 \times 10^{4}$ nearly. Hence if all the ions which reach and are absorbed by the condenser plates actually convey electric charge, less than $n_{0}=10$ ions per cubic centimeter occur in the saturated emanation contiguous to the surface of the phosphorus grid.

If now, instead of $U=1 \mathrm{~cm} . / \mathrm{sec}$. for the field of a volt per centimeter, the absorption velocity $k=.3 \mathrm{~cm}$. $/ \mathrm{sec}$. found in the absence of an electric field (Am. Journ., March), were taken, the number $n_{0}$ would be about 3 times larger; in such a case a special mechanism of electrolysis, as I endeavored to sketch it elsewhere, is in question. What I wish chiefly to point out, however, is that the order of the velocities $U$ and $k$, obtained from such widely different experiments, is about the same. Indeed if one supposes that but $1 / 3$ of all the ions travel in a given cardinal direction, $3 k$ will replace $k$ in the above estimates, and the close proximity of $3 k$ and $U$ is even more striking.

Brown UnIversity, Providence, R. I.

$$
\text { C. Barus. }
$$

\section{SCIENTIFIC BOOKS.}

Report of the U.S. Commissioner of Patents to Congress for the year ending December 31, 1900. Washington, Government Printing Office. 8vo. 1901. Pp. 19.

Among the many causes which have conspired to give the United States its present leading position in the industrial world, it may be doubted whether any single influence has been more potent than that liberal system of patent law which was established in the days of Washington and Hamilton, and which has been constantly under revision, usually and until lately with improvement, throughout the century. That defect which permits the inventor to secure a patent upon the simple presentation of a written claim, with a drawing or a diagram, and without any real work in successful reduction of the scheme to practise, and that which allows the inventor to secure indefinite retention of his legal claim-by the equally simple expedient of so wording his claims that the examiner will be sure to object, taking two years to frame another objectional claim, repeating this process, until the time is ripe for gathering in a profit-will be remedied whenever the committees of Congress choose. The few defects in the existing system are capable of instant remedy and its excellent features far outweigh its faults. That the Congress, the Commissioner, the public and especially the patent attorneys permit defects to remain is unfortunate; but it remains nevertheless the fact that we have the best system of patent-law yet produced and that it has done much and is still doing much to stimulate invention, to promote the efficiency of manufactures and to give prosperity to the country and to its average citizen. No more important duty lies with the legislative branch of the Government than that of sustaining and perfecting this code.

The Commissioner reports annually to the Congress. In the report before us he states the total receipts for the year 1900 at $\$ 1,350,828.53$, the expenditures $\$ 1,260,019.62$ and the profits for the year as the balance, $\$ 90 ; 808.91$.

The Patent Office has always made a profit on its business with the usually poor nventor, and this extortion of money from the greatest benefactor which this country knows in industrial fields has permitted the accumulation of an enormous sum, now reported by the Commissioner as $\$ 5,177,458.55$ in the United States Treasury, standing at that figure on the books of the Treasurer to-day. In other words, the poor inventor has contributed not only thous. ands of millions to the wealth of the nation, 